\title{
Participação econômica dos membros: O tratamento jurídico e contábil do capital social no direito brasileiro
}

\author{
(Member economic participation: legal and account treatment \\ of the capital on the Brazilian law)
}

\author{
Mario de Conto 1 \\ Paola Richter Londero² \\ Faculdade de Tecnologia do Cooperativismo-ESCOOP (Brasil)
}

Sumário: Introdução. I. Identidade Cooperativa e o Direito Internacional. II. O Capital Social das Cooperativas e as Normas Internacionais de Contabilidade. III. Discussão contábil e jurídica no Brasil. Considerações Finais. Referências Bibliográficas.

Summary: Introduction. I. Cooperative Identity and International Law. II. The Social Capital of Cooperatives and the International Accounting Standards. III. Accounting and legal discussion in Brazil. Final considerations. Bibliographic references.

Resumo: De acordo com o 3. Princípio Cooperativista da Participação Econômica dos Membros, os sócios contribuem de forma equitativa e democraticamente controlam o capital da sua cooperativa, sendo que parte desse capital é geralmente de propriedade comum. Tradicionalmente, o capital social foi entendido, do ponto de vista jurídico-contábil, como integrante do patrimônio líquido das Cooperativas. Recentemente, o International Accounting Standards Board, através das normas internacionais de contabilidade, compreendeu que o Capital Social deve ser classificado como uma obrigação e, portanto, como um passivo da Cooperativa. Tal classificação traz consequências, principalmente pelo aumento dos índices de endividamento dessas en-

1 Doutor em Direito. Coordenador de Ensino, Pesquisa e Extensao da Faculdade de Tecnologia do Cooperativismo-ESCOOP. Professor de Direito Cooperativo em cursos de graduacao e pos-graduacao. Advogado. Gerente Juridico do Sistema OCERGS-SESCOOP/RS. Correo electronico: mario-deconto@ocergs.coop.br

2 Mestre em Controladoria e Contabilidade pela Faculdade de Administração, Economia e Contabilidade da Universidade de São Paulo - USP - Riberão Preto. Professora Pesquisadora da Faculdade de Tecnologia do Cooperativismo - ESCOOP. 
tidades. Assim, o presente artigo analisa o 3. ${ }^{\circ}$ Princípio do Cooperativismo, a sua regulação no Direito Internacional e o tratamento contábil-jurídico atribuído ao capital social no Brasil.

Palavras chave: Cooperativas, Direito Cooperativo, Contabilidade Cooperativa.

Abstract: Under the Cooperative Principle of Members' Economic Participation, members contribute equitably and democratically control the capital of their cooperative, part of which is generally owned jointly. Traditionally, the share capital was understood, from a legal-accounting point of view, as part of the net worth of the Cooperatives. Recently, the International Accounting Standards Board, through international accounting standards, understood that Social Capital should be classified as an obligation and therefore as a liability of the Cooperative. This classification has consequences, mainly due to the increase in the indebtedness indexes of these entities. Thus, this article analyzes the $3^{\text {rd }}$ Principle of Cooperativism, its regulation in International Law and the accounting-legal treatment attributed to social capital in Brazil.

Keywords: Cooperatives, Cooperativa Law, Cooperative Accounting. 


\section{Introdução}

A Aliança Cooperativa Internacional (1995), em sua declaração sobre a Identidade Cooperativa, reconhece sete princípios a serem observados pelas Cooperativas no mundo. São eles (1) Adesão Livre e Voluntária; (2) Controle Democrático pelos Sócios; (3) Participação econômica dos Sócios; (4) Autonomia e Independência; (5) Educação, formação e informação; (6) Cooperação entre Cooperativas; (7) Preocupação com a comunidade.

De acordo com o Princípio da Participação Econômica dos Sócios, a Aliança Cooperativa Internacional (2017) declara que sócios contribuem de forma equitativa e democraticamente controlam o capital da sua cooperativa. Pelo menos parte desse capital é geralmente propriedade comum da cooperativa. Os membros geralmente recebem uma compensação limitada, se houver, no capital subscrito como condição de associação. Os membros atribuem excedentes para qualquer um dos seguintes propósitos: desenvolver a sua cooperativa, possivelmente através da constituição de reservas, parte das quais, pelo menos, seriam indivisíveis; beneficiando os membros proporcionalmente às suas transações com a cooperativa; e apoiar outras atividades aprovadas pelos membros.

O Princípio pode ser dividido em duas partes, identificadas à dupla qualidade do sócio de Cooperativas, enquanto (1) proprietário e (2) usuário. Enquanto proprietário, o sócio participa com a formação do capital social que será responsável pelo desenvolvimento das atividades da Cooperativa e se consubstancia em garantia perante terceiros. Enquanto usuário, o sócio realiza operações com a Cooperativa, no âmbito de seu objeto social. Trata-se, efetivamente, das transações decorrentes da atuação com a Cooperativa em atendimento à necessidade comum dos associados.

O presente artigo pretende examinar, quanto à porção proprietário, o tratamento jurídico contábil do capital social das Cooperativas no âmbito do Direito Brasileiro e contribuir com a justificativa teórica da necessária reafirmação histórica das características das Cooperativas, como meio de preservação de sua identidade e de seu regime jurídicocontábil adequado.

\section{Identidade Cooperativa e o Direito Internacional}

Henry (2012) refere que na atualidade, verificam-se duas tendências opostas em relação a evolução do Direito Cooperativo: (1) a rea-

Boletín de la Asociación Internacional de Derecho Cooperativo 
firmação das características peculiares das Cooperativas, na esteira das primeiras legislações mundiais que buscavam diferenciar a sociedade cooperativa das demais sociedades existentes, caracterizando-a como uma sociedade de pessoas, de fins não lucrativos, orientada à satisfação das necessidades de seus membros e de outro, a um movimento de "societarização» das Cooperativas, como uma imposição de padronização dos agentes econômicos que operam em uma economia globalizada, notadamente considerando-se as normas de direito concorrencial e as chamadas normas internacionais de contabilidade.

A tendência de "societarização» das Cooperativas pelo Direito põe em grave risco a identidade cooperativa, o que acarreta reflexos diretos ao seu regime fiscal e o seu tratamento jurídico adequado.

De acordo com Henry (2012) além de mudar profundamente os padrões de produção, a globalização também está perturbando as noções de lei e os processos de fazer leis. Outro fenômeno é a terceirização da elaboração de leis por ministérios e parlamentos a empresas de direito privado. O fenômeno afeta diretamente a legislação cooperativa são, como foi dito, a quase padronização

Henry (2013), ao comentar as regulações privadas, cita como exemplo as emanadas pelo International Accounting Standards Board (IASB), referindo que em tempos de diminuição da participação democrática no processo legislativo, crescente informalização das economias, lei globalizadora e uma crescente influência do estabelecimento de padrões por atores privados sobre os legisladores públicos, a legitimidade democrática de um instrumento precisa ser considerada ao se avaliar seu valor jurídico.

Em termos de Direito Internacional, segundo a Recomendação 193 da Organização Internacional do Trabalho, em seu parágrafo 7 (2), «as cooperativas deveriam beneficiar de condições conformes com a legislação e prática nacionais que não sejam menos favoráveis do que aquelas que beneficiam as outras formas de empresa ou organização social. Os governos deveriam adotar, caso seja necessário, medidas de apoio em favor das atividades das cooperativas que prossigam certos objetivos das políticas sociais e públicas, tais como a promoção do emprego ou a realização de atividades dirigidas a grupos e regiões desfavorecidas. Estas medidas poderiam incluir, nomeadamente, e na medida do possível, benefícios fiscais, empréstimos, doações, facilidades de acesso aos programas de obras públicas e de disposições especiais em matéria de mercados públicos».

Para Henry (2013), a segunda frase do par. 7 (2), citada acima, implica a obrigação de manter a natureza distinta das cooperativas, não apenas através da lei cooperativa, mas também através de outras leis, 
por exemplo, direito do trabalho, direito tributário, direito da concorrência e normas internacionais de contabilidade manter regras, especialmente aquelas elaboradas pelo IASB. De acordo com o autor, a relevância prática do princípio da igualdade de tratamento requer considerar as diferenças estruturais em comparação com outros tipos de empresas em todos esses campos do direito. Essas diferenças estruturais podem ser derivadas de uma interpretação dos valores e princípios cooperativos.

Nesse sentido, processo de adoção das International Financial Reporting Standards (IFRS), seus efeitos e consequências, precisa ser analisado com cautela nas Cooperativas para que não exista conflito com valores e princípios cooperativos, bem como a estrutura de funcionamento das cooperativas. Segundo Lourenço e Branco (2015) mesmo que inúmeras pesquisas tenham revelado o aumento da qualidade da informação contábil para as empresas adotantes do IFRS, inclusive para os usuários dessa informação, ainda são necessários cuidados com o processo de generalização, sendo que em determinados casos, nem todas as empresas e nem todos os usuários saem beneficiados. Usualmente, os estudos sobre os efeitos da adoção das normas contábeis se concentram nas organizações de finalidade lucrativa, em especial em companhias abertas. Contudo, outras organizações também fazem parte do mercado e são afetadas pelas Normas Internacionais de Contabilidade, sendo esse o caso das cooperativas.

Para Lourenço e Branco (2015, p.128) «apesar das vantagens usualmente associadas à convergência para as IFRS, o efeito da adoção desse conjunto de normas ainda permanece a ser debatido», principalmente para organizações que apresentam aspectos singulares, tais como as cooperativas. É claro que as Normas Internacionais de Contabilidade são elaboradas para serem aplicadas, independente do sistema político, econômico, cultural, jurídico ou fiscal dos países que a adotem, e, independente do setor, tamanho, complexidade, multinacionalidade, endividamento, etc. da entidade que reporta a informação (Weffort, 2003), contudo, não é possível negar que tais características desses subsistemas sociais, bem como os aspectos estruturais empresarias não gerem atritos com o processo de adoção das IFRS (Lourenço, Sarquis, Branco e Pais, 2015).

Para Jeanjean e Stolowy (2008) essa falta de análise e reflexão sobre determinadas características estruturais pode prejudicar a qualidade da informação contábil, em casos específicos. Os autores complementam a análise indicando que utilizar regras iguais é uma condição necessária, mas talvez, insuficiente por si só para assegurar a qualidade da informação. Nesse sentido, Kvall e Nobes (2010), apontam que vá- 
rios países tem dificuldades para eliminar suas características das práticas contábeis anteriores a adoção da IFRS, uma vez que em uma primeira análise parecem estar em melhor consonância com os subsistemas sociais do país. Por outro lado, esse processo de «uniformidade aparente» no tocante às normas internacionais de contabilidade gera problemas de comparabilidade da informação contábil, que por sua vez também irá prejudicar a qualidade da informação (Nobes, 2013).

Na América Latina, especificamente no Brasil, a discussão sobre as Normas Internacionais de Relatórios Financeiros (International Financial Reporting Standards-IFRS) aplicadas à sociedades cooperativas, ganhou força perante tentativa de aplicação da International Financial Reporting Interpretations Committee (IFRIC) 2 em tais sociedades. Perante essa norma, o capital social entendido, do ponto de vista tratamento jurídico-contábil, tradicionalmente como integrante do patrimônio líquido das Cooperativas, através das normas internacionais de contabilidade, seria reclassificado como uma obrigação da Cooperativa e, portanto, como um passivo da entidade.

Para a Organização das Cooperativas Brasileiras (2017), essa imposição trazida pela IFRIC 2 reflete a inadequação e falta de compreensão dos valores e princípios cooperativos, bem como dos prejuízos que tal norma contábil poderia trazer para o funcionamento das cooperativas, visto que de acordo com Vialcanet e Salas (2014) e Vialcanet e Roig (2013) a reclassificação causa a piora significativa nos índices econômico-financeiros das cooperativas, devido ao aumento nos índices de endividamento e redução da solvência das cooperativas, que poderia dificultar o acesso ao crédito por parte de tais entidades.

Cracogna (2013) ao tratar da Lei Marco para Cooperativas da América Latina, refere que o capital é variável e ilimitado e é parte do patrimônio líquido da cooperativa, esclarecendo dúvidas sobre sua natureza e sistema contábil. Segundo o autor essa definição é particularmente importante, considerando-se o requisito das Normas Internacionais de Relatórios Financeiros (International Financial Reporting Standards-IFRS) do International Accounting Standards Board (IASB), que considera que o capital social faz parte dos passivos de uma cooperativa.

\section{O Capital Social das Cooperativas e as Normas Internacionais de Contabilidade}

De acordo com a Aliança Cooperativa Internacional (2015) as cooperativas enfrentam o desafio de atender às exigências regulatórias impostas a elas devido à falta de compreensão da natureza e da essên- 
cia de um negócio cooperativo que é diferente da empresa de capital aberto investidor / capital, que é o modelo de negócios padrão ensinado nas escolas de negócios e na maioria dos textos econômicos. Há uma necessidade de desenvolver um maior entendimento entre os governos e órgãos reguladores da forma cooperativa de empresa, sua estrutura de funcionamento, seu lugar na economia moderna e sua capacidade de ser econômica, cultural e socialmente transformadora quando eles são capazes de operar dentro de um ambiente apropriado regime jurídico e regulatório.

Contemporaneamente, verifica-se que tal dinâmica externa afeta ao Direito através da forte pressão exercida por regulações internacionais - por vezes emanadas de organismos privados - na construção de normas jurídicas nacionais. Como exemplo aplicável ao Direito Societário —afetando diretamente às Cooperativas - estão as chamadas «Normas Internacionais de Contabilidade» —IFRS (International Financial Reporting Standards), elaboradas pelo «Conselho Internacional de Padrões Contabilidade»- IASB (Internationational Accounting Standards Board), uma organização privada e independente de governos.

Não obstante à sua paraestatalidade e à não cogência das normativas elaboradas pelo IASB, verifica-se que o processo de globalização econômica impõe a padronização das sociedades como decorrência da necessidade de desenvolvimento do comércio internacional. Tal padronização, focada na "eficiência» do mercado e na redução dos custos de transação, é realizada sem a devida análise das peculiaridades dos tipos societários e das legislações nacionais (Weffort, 2003).

Notadamente a IAS 32, que trata de instrumentos financeiros, busca padronizar, em nível mundial, a classificação dos instrumentos financeiros das empresas em passivos (liabilities) e patrimônio (equity). Tal padronização é de interesse das grandes empresas transnacionais, constituídas sob a forma de sociedade anônima e erigidas ao modelo empresarial 'standard' do sistema capitalista. Justifica-se tal padronização em virtude da necessidade de que tais empresas transnacionais tenham maior facilidade de acessar recursos financeiros através da emissão de ações e de sua negociação em mercados mobiliários em todo o mundo.

No que concerne às Cooperativas, a IAS 32 culminou na IFRIC 2, aprovada em 2004, com vigência a partir de 2005, dispondo sobre Members' Shares in Co-operative Entities and Similar Instruments. Essa interpretação contábil específica direcionada para sociedades cooperativas, gerou uma grande repercussão no cooperativismo, uma vez que tal norma tem implicações diretas na classificação do capital social das Cooperativas (Vialcanet e Salas, 2014). 
As normas internacionais de contabilidade sugerem que o Capital Social -historicamente classificado como patrimônio líquido da Cooperativa - seja reclassificado como um passivo. É claro, a norma possibilita que as quotas de cooperados classifiquem-se no patrimônio líquido, mas para isso é necessário que a entidade tenha o direito exclusivo e incondicional, total ou parcial, de definir se o cooperado pode efetuar, ou não, o resgate. Tal cláusula deve ser especificada por lei, regulamentos ou estatuto.

Essa solução proposta para a manutenção das quotas de capital no patrimônio líquido das cooperativas é mais complexa do que, a priori, pode parecer. As sociedades cooperativas dependem da aprovação da assembleia geral para alteração de cláusulas no estatuto, e como tal alteração não beneficiaria os cooperados uma vez que o resgate das quotas dependeria de aprovação da cooperativa, acredita-se que haverá resistência e dificuldades para que tais conseguirem incorporar cláusulas de restrição de resgate das quotas dos cooperados (Polo-Garrido, 2007). Ainda é possível argumentar que tal cláusula de direito exclusivo e incondicional, seja ela total ou parcial, se posiciona contra a essência e princípios do movimento cooperativista, tendo em vista o princípio de adesão livre e voluntária, que assim como dá a liberdade do cooperado entrar na sociedade cooperativa, também concede liberdade para seu processo de retirada, sem entraves como a cláusula de resgate de capital proposta pela IFRIC 2. De acordo com Bengoa (2009) essa alteração estatutária causaria danos consideráveis nos direitos econômicos dos membros da cooperativa, sendo necessário refletir até que ponto a adesão a uma norma contábil como essa é justificável.

A normatização é motivada na medida em que, uma vez que as quotas de capital dos associados são resgatáveis, constituiriam uma exigibilidade da cooperativa. ${ }^{3}$ Ademais, conforme expostos por Fernández Guadaño (2006), a não existência do direito do cooperado aos ativos líquidos da entidade também torna-se uma justificativa para o processo de reclassificação das quotas para o passivo.

Tal argumentação desconsidera a diferença que o capital exerce em uma empresa de capital e em uma sociedade cooperativa, bem como a compreensão do princípio da adesão livre e voluntária. O que se apresenta evidente é que essa padronização —ou societarização das Cooperativas - importa no risco de perda da identidade da cooperativa, o

3 AMORIM, Ana Luísa G. Cavallari de; BIALOSKORSKI NETO, Sigismundo. Impactos dos padrões internacionais de contabilidade nas cooperativas brasileiras. 
que traz repercussões muito mais relevantes que a questão do tratamento do capital de tais sociedades, mas pode inclusive justificar a desnecessidade de um tratamento diferenciado, adequado a suas características.

É nesse sentido que a defesa da Identidade Cooperativa se apresenta como um imperativo de seu tratamento jurídico adequado, o que traz consequências diretas para o seu tratamento jurídico-contábil.

Ao considerar as diretrizes do International Accounting Standards Board sobre o tratamento contábil e financeiro das ações dos membros da cooperativa a Aliança Cooperativa Internacional (2015), advoga que a quota capital dos sócios fazem parte dos recursos de capital próprios de uma cooperativa que garantem a continuidade da cooperativa nos negócios. Em outras palavras, o capital dos membros deve ser tratado como parte do capital social da cooperativa não como dívida (um passivo no balanço patrimonial da cooperativa).

Entende a Aliança Cooperativa Internacional (2015) que as cooperativas precisam continuar pressionando para que o tratamento contábil global consistente do capital social e das reservas indivisíveis dos membros seja tratado como parte do capital social de uma cooperativa, não como um passivo, porque capital pode absorver as perdas de uma cooperativa. Segundo a Organização, para conseguir isso as cooperativas devem garantir que o capital social e as reservas indivisíveis dos membros estejam sujeitos a qualquer risco de distribuição aos atuais membros da cooperativa. A indivisibilidade deve continuar a ser a regra para evitar qualquer apropriação ou desvio na tarefa de alcançar este tratamento contábil global.

\section{Discussão contábil e jurídica no Brasil}

No Brasil, a IFRIC 2 foi traduzida e proposta como a Interpretação Técnica ICPC 14. Tal interpretação foi aprovada pelo Comitê de Pronunciamentos Contábeis (CPC), em sua 53. ${ }^{a}$ Reunião Ordinária, realizada em novembro de 2010, contudo, não entrou em vigência.

Nesse período, a Organização Brasileira das Cooperativas iniciou tratativas com o Conselho Federal de Contabilidade, CPC e Instituto dos Auditores Independentes do Brasil (Ibracon), para postergação da adoção da ICPC 14 visto os possíveis impactos nos índices de avaliação econômico-financeiros, que poderiam prejudicar o acesso ao crédito por parte das Cooperativas já que índices de endividamento seriam elevados e, em alguns casos, cláusulas de empréstimos seriam quebradas. Ademais, na percepção da entidade, tal classificação das quotas con- 
forme a proposta da ICPC 14 não demonstrava a essência das quotas de capital das Cooperativas no Brasil.

Através das negociações realizadas, houve a emissão da Resolução do CFC n. ${ }^{\circ} 1.324$, postergando pelo primeira vez a vigência do ICPC 14 para $1 .^{\circ}$ de janeiro de 2012. A segunda postergação de vigência ocorreu em 25 de novembro de 2011, quando por meio da Resolução do Conselho Federal de Contabilidade n. 1.365 a vigência foi alterada para $1 .^{\circ}$ de janeiro de 2016.

Nesse meio tempo, a Organização Brasileira das Cooperativas, por meio de sua representação política, consegui a aprovação da Lei n. ${ }^{\circ}$ 13.097, com a inclusão do $\S 4 .^{\circ}$ no Art. 24 na Lei n. ${ }^{\circ}$ 5.764/1971. O dispositivo determina, in verbis:

Art. 24. O capital social será subdividido em quotas-partes, cujo valor unitário não poderá ser superior ao maior salário mínimo vigente no País.

(...)

$\S 4^{\circ}$ As quotas de que trata o caput deixam de integrar o patrimônio líquido da cooperativa quando se tornar exigível, na forma prevista no estatuto social e na legislação vigente, a restituição do capital integralizado pelo associado, em razão do seu desligamento, por demissão, exclusão ou eliminação. (Incluído pela Lei . $^{\circ}$ 13.097, de 2015.)

Nesse sentido, a partir de tal alteração legislativa, as quotas de cooperados devem ser classificadas no patrimônio líquido até o momento em que as quotas se tornarem exigíveis em razão da demissão, exclusão ou eliminação do cooperado. Com essa alteração e frente as manifestações a favor e contrárias a vigência da ICPC 14, o CFC decidiu adiar a aplicação da ICPC 14 para janeiro de 2017 com o argumento da necessidade de uma maior discussão sobre a questão. Já em 2016, por meio da resolução n. ${ }^{\circ} 1.516 / 2016$, ainda frente ao impasse sobre o assunto, a Câmara Técnica do CFC, responsável pela questão, decidiu adiar mais uma vez a vigência para $1 .^{\circ}$ de janeiro de 2018.

Durante o ano de 2017, a Câmara Técnica seguiu com as discussões sobre o assunto, inclusive analisando artigos acadêmicos sobre os possíveis impactos da ICPC 14 no Brasil ${ }^{4}$, a exemplo do que aconteceu

4 Londero, P. R. \& Santos, A. dos (2017). ICPC 14: Os Impactos dessa Norma Contábil nas Sociedades Cooperativas. In: Anais do XVII USP International Conference In Accounting, conforme consta na Ata $254 .^{a}$ da Reunião da Câmara Técnica, de 17 e 18 de maio de 2017. 
na Espanha onde várias pesquisas foram divulgadas sobre o assunto (Vialcanet; Salas, 2014, Vialcanet; Roig, 2013, Álvarez Pérez; Suárez Álvarez, 2014, Arias Terés; Montegut Salla, 2012, Álvarez, 2010).

Concomitante com as discussões sobre a ICPC 14, o CFC também dedicou esforços para a elaboração da ITG 2004, que apresenta reformulações contábeis da NBC T 10.8, norma que anteriormente regulamentava as especificações contábeis das Cooperativas. Em 24 novembro de 2017, o Plenário do Conselho Federal de Contabilidade emitiu a aprovação da ITG 2004, revogando a NBC T 10.8, e dispondo entre seus itens, dois itens diretamente vinculados ao ICPC 14. ITG 2004 em seus itens 20 e 21 :

Item 20. O capital social da entidade cooperativa é formado por quotas-partes, que devem ser registradas de forma individualizada, segregando o capital subscrito e, por dedução, em conta distinta o capital a integralizar, no Patrimônio Líquido, podendo, para tanto, serem utilizados registros auxiliares.

Item 21. Os valores a restituir aos associados demitidos, eliminados e excluídos, ou qualquer outro motivo previsto no estatuto social devem ser transferidos para contas passivas de capital social a restituir, assim que a entidade cooperativa receber o pedido de demissão ou deliberar pela eliminação ou exclusão do cooperado, conforme disposto no $\S 4$. $^{\circ}$ do Art. 24 da Lei n. ${ }^{\circ}$ 5.764/1971. (grifo nosso, p. 3)

Com a aprovação dessa norma contábil para cooperativas, o CFC acabou por determinar que a ICPC 14 não iria entrar em vigência no Brasil, visto que o próprio órgão responsável por determinar a vigência das normas aprovadas pelo Comitê de Pronunciamento Contábeis, responsável pela tradução das normas internacionais de contabilidade, reconhece a manutenção das quotas dos cooperados no patrimônio líquido da entidade.

Contudo, é preciso destacar que o Conselho Federal de Contabilidade somente possui autonomia para determinar a não adoção da ICPC 14 para as sociedades cooperativas que possuem suas demonstrações contábeis reguladas por esse órgão. No caso de ramos regulados por órgãos específicos, como é o caso do crédito, saúde e infraestrutura no Brasil, a decisão pertence a cada órgão regulamentador, visto que o Comitê de Pronunciamento Contábil não recuou na aprovação da ICPC 14, tradução da IFRIC 2, em virtude, dentre outros fatores, da necessidade de se manter a convergência com as normas internacionais de contabilidade. 


\section{Considerações finais}

As pressões decorrentes do tratamento contábil das Cooperativas (Normas internacionais da contabilidade), do direito de concorrência - que sob a falsa premissa da padronização de tratamento entre todas as empresas haveria isonomia- exigem do movimento cooperativo a articulação com o Estado no sentido de que a legislação reconheça as características peculiares das Cooperativas.

No Brasil, o Conselho Federal de Contabilidade, de certa forma, reconheceu que as Cooperativas apresentam peculiaridades, advindas da sua natureza, princípios e forma de funcionamento únicos, o que torna necessário discutir a ampla aplicação das normas internacionais de contabilidade sobre tais entidades, conforme consta na Ata 254. ${ }^{a}$ da Reunião da Câmara Técnica, de 17 e 18 de maio de 2017. Assim, como ocorreu com a IFRIC 2, traduzida e aprovada como ICPC 14, é necessário analisar não só os possíveis impactos trazidos pela norma contábil, mas também verificar o quão aderente se encontra a sua peculiaridade.

O artigo reforça, nesse sentido, a importância da atuação dos órgãos representativos — no caso presente, da Organização das Cooperativas Brasileiras - na defesa da identidade das Cooperativas no Direito Brasileiro e da necessária consideração de suas peculiaridades quando de sua regulação.

\section{Referências bibliográficas}

ALTHAUS, Alfredo A. 1977. Tratado de Derecho Cooperativo. Córdoba: Zeus Editora.

ÁlVAREZ PÉREZ, B. \& Suárez Álvarez, E. 2014. «Calificación de instrumentos financieros en las sociedades cooperativas a raíz de la NIC 32. La solución española». Revista Innovar Journal Revista de Ciencias Administrativas y Sociales, 25(9): 9-20.

ÁlVAREZ, M. B. 2010. "Impacto del nuevo concepto de patrimonio neto en las socie-dades cooperativas». Partida Doble, 217: 58-68.

ARIAS, B. \& Montegut, Y. 2012. "Los efectos de la normativa contable en las sociedadescooperativas». Revista de Contabilidad y Dirección, 14: 183201.

BENGOA, I. A. 2009. "Accounting in a cooperative company». International Journal of Technology Management and Sustainable Development, 8(1): 57-67.

BRASIL, Lei n. ${ }^{\circ}$ 13.097. 2015. "Altera o art. 24 da Lei no 5.764», de 16 de dezembro de 1971. 19 de janeiro de 2007. Diário Oficial da União, Poder Legislativo, Brasília, DF. 
BRASIL, Lei n. ${ }^{\circ}$ 5.764. 1971. «Define a política nacional do cooperativismo, institui o regime jurídico das sociedades cooperativas», e dá outras providências. 16 de dezembro de 1971. Diário Oficial da União, Poder Legislativo, Brasília, DF.

COMITÊ DE PRONUNCIAMENTO CONTÁBIL (CPC). 2010. «Interpretação Técnica ICPC 14 - Cotas de Cooperados em Entidades Cooperativas e Instrumentos Similares». Acesso em 22 de maio de 2018, http://www.cpc.org. $\mathrm{br} / \mathrm{CPC} /$ Documentos-Emitidos/Interpretacoes/Interpretacao?/d=23

CONSELHO FEDERAL DE CONTABILIDADE, «Resolução n. ${ }^{\circ}$ 1.324». 2011. Altera a data da aplicação de itens das NBC Ts 19.33 e 19.41 que tratam da apresentação do capital social das sociedades cooperativas. 18 de fevereiro de 2011. Diário Oficial da União, Brasília, DF.

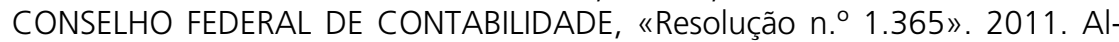
tera a data da adoção obrigatória de que trata o Art. $1 .^{\circ}$ da Resolução CFC n. ${ }^{\circ}$ 1.324/11. 25 de novembro de 2011. Diário Oficial da União, Brasília, DF.

CONSELHO FEDERAL DE CONTABILIDADE. 2016. «CFC prorroga, por mais um ano, a reclassificação das cotas-partes das sociedades cooperativas». Acesso em 24 de maio de 2018, http://cfc.org.br/noticias/cfc-prorroga-pormais-um-ano-reclassificacao-das-cotas-partes-das-sociedades-cooperativas/

CONSELHO FEDERAL DE CONTABILIDADE, "Resolução n. ${ }^{\circ} 1.516 » .2016$. Altera a data da adoção obr. do Art. $1 .^{\circ}$ da Res CFC n. ${ }^{\circ} 1.324 / 11.05$ de dezembro de 2016. Diário Oficial da União, Brasília, DF.

CONSELHO FEDERAL DE CONTABILIDADE. 2017. "Ata da 254. ${ }^{\text {a }}$ Reunião da Câmara Técnica». 17 e 18 de maio de 2017. Acesso em 24 de maio de 2018, http://cfc.org.br/wp-content/uploads/2017/04/Ata-C\%C3\%A2maraT\%C3\%A9cnica-254-Maio-de-2017.pdf

CONSELHO FEDERAL DE CONTABILIDADE. «ITG 2004 - Entidades Cooperativas». 2017. Acesso em 04 março de 2018. Acesso em 24 de maio de 2018, http://cfc.org.br/wp-content/uploads/2016/02/ITG_2004_aud.docx

CRACOGNA, Dante. 1980. Estudios de Derecho Cooperativo. Buenos Aires: Intercoop.

CRACOGNA, Dante. 2013. The Framework Law for the Cooperatives in Latin America. In: International Handbook of Cooperative Law. Berlin: Springer.

CRACOGNA, Dante. 2004. O Ato Cooperativo na América Latina. In: Ato Cooperativo e seu adequado tratamento tributário. Belo Horizonte: Mandamentos.

$\mathrm{FICl}$, Antonio. 2013. An Introduction to Cooperative Law In: International Handbook of Cooperative Law. Springer-Verlag, Heidelberg.

FERNÁNDEZ GUADAÑO, J. 2006. «Diferentes consideraciones en torno al capital socialde las sociedades cooperativas». Revista de Estudios Cooperativos (REVESCO), 88: 42-61.

FRANKE, Walmor. 1978. Direito das Sociedades Cooperativas. São Paulo: Saraiva.

GALGANO, Francesco. 2003. II nuovo diritto societario. Padova: CEDAM. HENRY, Hagen. 2012. Guidelines for cooperative legislation. Geneva: ILO. 
HENRY, Hagen. 2013. Public International Cooperative Law. In: International Handbook of Cooperative Law. Berlin: Springer.

INTERNATIONAL ACCOUNTING STANDARDS BOARD. 2004. «IFRIC 2 - Members' Shares in Co-operative Entities and Similar Instruments». Acesso em 24 de maio de 2018, https://www.iasplus.com/en/standards/ifric/ifric2

INTERNATIONAL CO-OPERATIVE ALLIANCE. 2015. "Notas de orientación para los principios cooperativos». Acesso em 24 de maio de 2018, https://ica. coop/en/media/resources

INTERNATIONAL CO-OPERATIVE ALLIANCE. 2017. "Statement on the Cooperative Identity». Acesso em 24 de maio de 2018, https://ica.coop/en/ whats-co-op/co-operative-identity-values-principles

JEANJEAN, T., \& STOLOWY, H. 2008. «Do accounting standards matter? Na exploratory analysis of earnings management before and after IFRS adoption». Journal of Accounting and Public Policy, 27(6): 480-494.

KVALL, Erlend \& Nobes, Christopher. 2010. «International differences in IFRS policy choice: a research note». Accounting and Business Research, 40(2).

LOURENÇO, I.M.F.C. \& BRANCO, M.E.M.A.D.C. 2015. "Principais consequências da adoção das IFRS: Análise da literatura existente e sugestões para investigação futura». Revista de Contabilidade \& Finanças. doi: 10.1590/1808-057x201500090

LOURENÇO, I., SARQUIS, R., BRANCO, M. PAIS, C. 2015. «Extending the Classification of European Countries by their IFRS Practices: A Research Note». Accounting in Europe, 12(2).

MAULEÓN MÉNDEZ, Emilio; GENOVART BALAGUER, Juana Isabel. 2016. «Pongamos orden en el régimen contable de las sociedades agrarias de transformación». REVESCO. Revista de estudios cooperativos, núm. 122, pp. 219-251.

MÜNKNER, Hans-H. 2013. Report on the American-European Meeting on the Law of Co-operatives and Organisations based on Solidarity. Bogotá/Colombia.

NAMORADO, Rui. 2005. Estudos de Direito Cooperativo. Coimbra: Almedina.

NAMORADO, Rui. 2000. Introdução ao direito cooperativo. Coimbra: Almedina.

NOBES, C. 2013. The Continued Survival of international differences under IFRS. Accounting and Business Research, 43(2).

ORGANIZAÇÃO BRASILEIRA DAS COOPERATIVAS (OCB). «CFC afasta aplicação de norma prejudicial a cooperativas». Acesso em 20 de maio de 2016. Acesso em 24 de maio de 2018, http://somoscooperativismo.coop. br/noticia/20953/cfc-afasta-aplicacao-de-norma-prejudicial-a-cooperativas

POLO GARRIDO, Fernando. 2007. «Impactos de las normas internacionales de información financiera en el régimen económico de las sociedades cooperativas». Revista de Economía Pública, Social y Cooperativa, 58: 83-108.

VIALCANET, R.B. \& SALAS, O.A. 2014. «Efectos económicos de la primera aplicación de las normas contables adaptadas a la NIC 32 en las cooperativas». Revista de Contabilidad - Spanish Accounting Review, 17(2): 201211. 
VIALCANET, R.B.; ROIG, L.C. 2013. "Estudi empíric sobre els efectes de I'aplicació de la NIC 32 a les cooperatives». Intangible Capital, 9(2): 392419.

VILLARROYA LEQUERICAONANDIA, María Begoña; RAMOS SÁNCHEZ, Sofía. 2018. «¿Proporciona La normativa contable española para organizaciones no gubernamentales el marco conceptual idóneo para la presentación de información económico-financiera transparente? Similitudes y diferencias con la normativa internacional aplicada por las 20 ONG más importantes del mundo». REVESCO. Revista de Estudios Cooperativos, núm. 128, pp. 212-247.

WEFFORT, E.J. 2003. Impacto do sistema educacional, sistema legal e mercado na harmonização das normas contábeis brasileiras em relação às normas internacionais. Tese de Doutoramento, EAC FEA USP.

ZUBIARRE ARTOLA, Miguel Ángel; ANDICOECHEA ARONDO, Lorea; SAITUA IRIBAR, Ainhoa. 2015. «Aplicación de la Orden EHA/3360/2010 sobre aspectos contables de las sociedades cooperativas: efectos en los fondos propios de las cooperativas de la Comunidad Autónoma del País Vasco». REVESCO. Revista de estudios cooperativos, núm. 118, pp. 180-201. 


\section{Derechos de autor}

El Boletín de la Asociación Internacional de Derecho Cooperativo es una revista de acceso abierto lo que significa que es de libre acceso en su integridad inmediatamente después de la publicación de cada número. Se permite su lectura, la búsqueda, descarga, distribución y reutilización legal en cualquier tipo de soporte sólo para fines no comerciales y según lo previsto por la ley; sin la previa autorización de la Editorial (Universidad de Deusto) o el autor, siempre que la obra original sea debidamente citada (número, año, páginas y DOI si procede) y cualquier cambio en el original esté claramente indicado.

\section{Copyright}

The International Association of Cooperative Law Journal is an Open Access journal which means that it is free for full and immediate access, reading, search, download, distribution, and lawful reuse in any medium only for non-commercial purposes, without prior permission from the Publisher or the author; provided the original work is properly cited and any changes to the original are clearly indicated. 